\title{
DYNAMICS OF ANXIETYAND PERCEIVED STRESS AMONG THE PARTICIPANTS IN THE XXV ANTARCTIC EXPEDITION
}

\author{
Galina Domuschieva-Rogleva, Tatiana Iancheva, Aleksander Shopov \\ National Sports Academy "Vassil Levski”, Sofia, Bulgaria
}

\begin{abstract}
The XXV Bulgarian Antarctic expedition on the Livingston isles, which included scientists and alpinists, began in November 2016. The participants' activities are highly dependent on the extreme conditions they are in.

The aim of the present researchis to studydynamics ofanxiety and perceived stress and to find a relation with the participants 'preferred strategies for coping with stress in highly risky activities in an extreme climatic and social environment.

Subject of the study were 21 participants in the XXV Bulgarian Antarctic expedition, mean age 27 and 70. We have used Bulgarian adaptation of: Spielberger's Anxiety Inventory (STAI); Questionnaire for perceived stress (PS-1) and Coping Orientations to Problems Expe-rienced scale-COPE 1. The first two tests were applied before the departure for Antarctica and before the return to Bulgaria.

The level of perceived stress in the beginning of the expedition issignificantly higher compared to the resultsobtained in the end of the expedition. Similar results were observed in terms of situational anxiety, which refers to the dynamic mental states. The cognitive engage-ment coping strategies are the main ones, whereas cognitive and emotional disengagement strategies are the least used.The results from the regression analysis show that the high levels of perceived stress has the biggest impact on the levels of anxiety in participants studied.

The present study adds to the understanding the role of anxietyand perceived stressin difficult and challenging missions in extreme conditions in highly risky activities.
\end{abstract}

Key words: coping strategies, risk-taking activity, cognitive engagement coping strategies

INTRODUCTION

There is a significant interest in the psychological changes and the functioning of the members of polar expeditions (Gunderson, 1974; Gunderson \& Pálinkás, 1991; Mihra, 2006; Pálinkás, Suedfeld \& Steel., 1995; Suedfeld, 2001; Khandelwal et al., 2015, 2017; Zimmeret al., 2013). In some research the influence of the internal self-concept, interpersonal relationships and personal characteristics on the activities in polar expeditions are sought (Pálinkás \& Johnson, 1990; Pálinkás, 2003; Rosnet, LeScanff \& Sagal, 2000).

Long-term stays in extreme environments, such as polar regions, may cause significant changes in individuals' health and well-being. The systematic overview of the literature aimed to map studies about the psychological effects on the participants in the Antarctic ex- peditions. The reviewed data were categorized and divided into two thematic fields: negative effects, resulting from harmful psychophysiological variations caused by exposure to the polar stressors, which may present seasonal symptom patterns, altering cognitive performance, mood and interpersonal relationships; and positive effects, such as salutogenic results arising from successful adaption to environmental adversities. Due to the great deal of evidence, it is suggested that protection factors should be promoted through preventive approaches, such as psychological training and support in order to reduce symptoms and generate satisfactory adaptation to Antarctica. al. 2000, 2004 (Zimmer et al., 2013)

At the end of 2016 and the beginning of 2017 XXV Bulgarian Antarctic expedition was held on Livingston Island with the par- 
ticipation of scientists working in different fields. During the expedition a number of projects in various scientific fields were realized. The participants' activities are highly dependent on the extreme conditions they are in. The climate there is characterized with frequent weather changes, strong winds, snowfalls, with one or two sunny and windless days a month. According to some researchers this is "the worst weather on earth". Antarctica is one of the most extreme and isolated environments on Earth. Average annual temperatures range from $-10^{\circ} \mathrm{C}$ on the coast to $-60^{\circ} \mathrm{C}$ at the interior, rendering Antarctica the world's largest desert. Antarctica is also the highest continent on Earth, with an average elevation of 2500m (King \& Turner 1997) which further contributes to the cold climate. Moreover, the nature of this environment renders it impossible to sustain human life without the aid of technology and complex operations, and its geographic isolation limits the availability of external assistance in medical and other emergencies (Lugg 2005). Despite substantial improvements in the living and working facilities provided for the participants in the expeditions (Lugg 2005), Antarctica remains a climatically, geographically, personally, and socially challenging environment. The impacts of physical, social, and psychologicalstressors on each participant's health and performance in Antarctica have been extensively documented. The influence of these challenges on individual, social, and occupational functioning, both short and long-term, cannot be underestimated. Thus, an understanding and appreciation of the processes leading to positive and negative outcomes associated with Antarctic employment is warranted as it provides for the development of both proactive prevention strategies as well as targeted intervention strategies to maximize outcomes (Palinkas \& Suedfeld 2007). Furthermore, enhanced knowledge regarding such processes may then be applied to populations working within other extreme environments similar to Antarctic conditions. However, undertaking such research agendas is challenging due to the difficulty in conducting longitudinal research studies on transient populations. A number of surveys within Antarctic cohorts have focused on the outcomes for the participants rather than to the processes leading to them (Norris et al., 2010). These conditions made us study some psychological characteristics of the participants in the expedition.

Stress is one of the most important psychological constructs in behavior science and that's why there are many approaches to its study. The first approach sees stress as a reaction of the organism to a given situation. The second approach accentuates on the situation or the stimuli independently from human perception and human reaction. The interactive approach defines stress as lack of balance between the demands of the environment and the individual abilities to cope, i.e. the level of stress is function of the ability of a person to answer the requirements of a given situation (Martens, et al.,1990).

Stress has become an inseparable part of human life and can be observed in every sphere of life. In conditions of physical extremities, such as that prevailing in the Antarctic, the routine undergoes a drastic alteration and stress relieving agents such as families, friends, and neighbours cease to exist. This requires an individual to psychologically shift gears to adapt to the new situation. Problems related to the individual's adjustment to close group interdependence, monotony of the environment and absence of accustomed sources of emotional gratification have been studied among groups of volunteers subjected to isolated Antarctic living for six to eight months at isolated bases (Mihra, 2006). In recent years, the area of psychological stress has made significant advances in understanding the relationship between physical environmental stresses and well-being. It deals with the im- 
pact of a wide range of negative outcome that otherwise seem to defy adequate explanation. With the beginning of influential work of Selye (1956) and Lazarus (1966), the environmental stress concept has led to ample amount of research on the properties of environment and its relationship with human behavior and health (Mihra, 2006).

Anxiety is a basic component of stress and it is not only a symptom or manifestation of stress, but also a cause of further stress (Girdano et al., 1990).

One of the most popular theories, a base of a number of surveys, outlines two types of anxiety - trait and state anxiety (Spielberg, 1983). Trait anxiety is viewed as a stable, acquired behavior disposition, personality trait which predisposes to perceiving a wide range of objectively safe stimuli as threatening ones and to reaction involving state anxiety, which significantly exceeds the objectively normal one.

State anxiety refers to the dynamic psychic conditions. It appears when an individual perceives a certain irritant or situation as including some actual or potential elements of danger, threat or harm. In the context of the concept of the genesis of stress, state anxiety is viewed as a function of the correlation between a certain need and the possibilities for its satisfaction. The lower probability of satisfying a need, combined with a high need, determined by inner or outer factors, lead to the manifestation of increased state anxiety (Spielberg, 1983). Anxiety, as a personality trait, affects performance. Individuals with low trait anxiety and high state anxiety find it easier to reach top achievement, while individuals with high trait and state anxiety have worse sports performance.

According to some authors, the outcome of cognitive and emotional processing usually leads to two general behavioral strategies: avoiding or actively dealing with the situation. Coping with stress is related to cognitive and behavioral efforts to cope with external and internal challenges and/or the conflict between them, which could be defined as an ordeal, or simply surpassing personal resources (Lazarus and Folkman, 1984). The copings used are the result of the dynamic interaction of personal and contextual influences. Strategies for coping with stress are divided into two major groups: problem focused coping, defined as active coping, and emotion focused copingpassive coping (Leventhal et al., 1993). Problem focused strategies are considered as appropriate to keep up the abilities for personal control with reference to the consequences in specific situations, as well as to their repeated occurrence in the future. Emotion focused copings are deemed as appropriate when individuals could do very little to control consequences or their repeated occurrence. Problem and emotion focused strategies differ in terms of their second evaluation of control (Folkman, 1992; Folkman and Lazarus, 1980).

The aim of the present research is to study the dynamics of perceived stress and anxiety and to find a relation with the participants' preferred stress coping strategies in highly risky activities in an extreme climatic and social environment.

Participants: The research was done among 21 participants in $25^{\text {rd }}$ Antarctic expedition - 17 men and 4 women, aged between 27 and 70, average age $-47,4$.

At the beginning of the research all participants were informed about the aim of the survey and their consent was obtained.

\section{Procedure}

During the expedition the participants filled out a number of psychological tests. The tests which evaluated perceived stress and anxiety were applied before the departure for Antarctica and before the return to Bulgaria. The difficulties in obtaining data were related to the different arrival and departure time of the members of the Antarctic expedition.

\section{RESEARCH METHODS}

1. Questionnaire for perceived stress 
(PS-1) developed by Cohen, Kamarck, Mermelstein, 1983 and adapted for Bulgarian conditions. It consists of 7 positively and 7 negatively formulated items. The researched people have to evaluate from 1 to 5 the frequency of their feelings and thoughts described by the items. The results characterize a relatively stable evaluation style for a given period of time (Karastoyanov, Russinova, 2000).

\section{State-Trait Anxiety Inventory (STAI)} (Spielberger, 1983) is a self-reported instrument. It was designed to assess levels of state anxiety and trait anxiety, through 40 items. All items are rated on a 4-point scale (e.g., from "Almost Never" to "Almost Always"). Higher scores indicate greater anxiety. State anxiety can be defined as a transient momentary emotional status that results from situational stress. Trait anxiety represents a predisposition to react with anxiety in stressful situations. This data set includes two STAI subscale score. Anxiety Form Y, its most popular version, has 20 items for assessing trait anxiety and 20 for state anxiety. State anxiety items include: "I am tense; I am worried" and "I feel calm; I feel secure." Trait anxiety items include: "I worry too much about something that really doesn't matter" and "I am content; I am a composed person." The questionnaire was adapted for Bulgarian conditions (Shtetinski, Paspalanov, 1989).

3. Coping Orientations to Problems Experienced scale - COPE - 1 (Carver, et al., 1989). The test evaluates various ways of coping with stress, used by people. It is adapted for Bulgarian conditions (Rusinova-Hristova, Karastoyanov, 2000) and it is optimized for sports practice (Georgiev at al., 2003). It includes 52 items, organized in 14 subscales: active coping, planning, suppression of competitive activities, restraint coping, seeking social support for instrumental reasons, seeking social support for emotional reasons, positive reinterpretation and growth, acceptance, turning to religion, focusing on and venting of emotions, denial, behavioral disengagement, mental disengagement, alcohol-drug disengagement.

These fourteen strategies have been joined together through factor analysis into three generalized secondary factors: cognitive engagement, emotional engagement, cognitive and emotional disengagement (Georgiev at al., 2009).

\section{RESULTS}

The results from the comparative analysis show there is no statistically significant difference between the average values of the researched variables with the participants in the expedition, differentiated by gender (criterion Mann-Whitney - U). A possible explanation could be found both in the small number of researched individuals, with the women being only four, and in the fact that the requirements for the psychic characteristics needed for participation in such an expedition are common and gender independent.

The obtained results show that the level of perceived stress in the beginning $(\mathrm{M}=32.06$; $\mathrm{SD}=7.78)$ is significantly higher compared to the results $(\mathrm{M}=28.31 ; \mathrm{SD}=10.35)$ (table 1$) \mathrm{ob}-$ tained at the end of the expedition $\left(\mathrm{T}=1,97^{*}\right)$ (criterion of Wilcoxon). The possible explanation could be found in the fact that during the last month before the expedition is a hectic one and related to the preparation, with lots of difficulties, ambiguities, details about the future activities, possible risks, and uncertainty about the fulfillment of the goals, which often depend on circumstances. The second result was obtained when the expedition was almost completed; the uncertainties were fewer and were related "only" to the trip back.

The ability for efficient coping with stressful events is a must for successful coping with challenges. Unsuccessful coping with acute stressors could harm different psychic processes such as concentration, direction of attention, activation (Anshel, 1990; Smith, 
1986). The efficient coping with stressful event requires the recovery of balance and imperturbability (Gould, et al., 1993) through favorable mental configuration (i.e. psychic readiness to respond to the next stimulus) and maintenance of optimal activation and concentration (Singer, 1982).

Similar results can be observed as regards state anxiety, which refers to the dynamic psychic conditions. It appears when an individual perceives a certain irritant or situation as including some actual or potential elements of danger, threat or harm. In the context of the concept of the genesis of stress, state anxiety is viewed as a function of the correlation between a certain need and the possibilities for its satisfaction. The lower probability of satisfying a need, combined with a high need, determined by inner or outer factors, lead to the manifestation of increased state anxiety. The level of state anxiety at the beginning of the expedition $(M=33.71$; $S D=8.62)$ is significant- ly higher than the results at the end of the expedition $(\mathrm{M}=28.08 ; \mathrm{SD}=8.72)\left(\mathrm{T}=2,01^{*}\right)$. It is probably because the situation was perceived as less dangerous or threatening. Regardless of the fact that trait anxiety is viewed as a stable personal characteristic, among the participants in the expeditions there is a statistically significant difference in the level of trait anxiety between the beginning of the expedition $(\mathrm{M}=36.35 ; \mathrm{SD}=8.85)$ and its end $(\mathrm{M}=29.92$; $\mathrm{SD}=8.05)(\mathrm{T}=2,32 * *)$. These results do not conform to postulates of trait anxiety in Spielberg's theory. The possible explanation could be that the participants were not able to distinguish between their condition at the moment of the testing and the way they felt generally.

The values of both types of anxiety are within the norms for the Bulgarian population (Shtetinski, Paspalanov, 1989).

Table 1. Average values of perceived stress and anxiety

\begin{tabular}{rrrrrr}
\hline & \multicolumn{2}{c}{ Min } & Max & M & \multicolumn{2}{c}{ SD } \\
\hline Perceived stress in the & 18.0 & 48.0 & 32.059 & 7.78 \\
beginning & 14.0 & 54.0 & 28.308 & 10.34 \\
Perceived stress in the end & 20.0 & 48.0 & 33.706 & 8.62 \\
State anxiety in the beginning & 20.0 & 48.0 & 28.077 & 8.72 \\
State anxiety in the end & 22.0 & 51.0 & 36.354 & 8.85 \\
Trait anxiety in the beginning & 21.0 & 45.0 & 29.923 & 8.04 \\
Trait anxiety in the end & & & & \\
\hline
\end{tabular}

The strategy of active coping is the most preferred by the subjects of the research in stress situations. Planning, positive reinterpretation and growth take the second and third place. The most avoided strategy is the use of alcohol and drugs. The participants of the research have the highest values in cognitively engaged coping strategies representing purposeful actions to overcome stress, recon- sidering and planning the ways and means of coping with it, and also rejecting and disregarding any tasks preventing or complicating coping. Emotionally engaged strategies - asking for advice, help and compassion have the average values, while cognitive and emotional disengagement coping - acceptance, seeking comfort in religion, alcohol and drugs are the ones most avoided (table 2). 
Table 2. Average values of coping strategies

\begin{tabular}{ccccc}
\hline Variables & Min & Max & M & SD \\
\hline 1 & 2.75 & 3.75 & 3.32 & .37 \\
2 & 2.50 & 4.00 & 3.22 & .46 \\
3 & 2.25 & 3.75 & 2.77 & .37 \\
4 & 2.25 & 3.50 & 2.63 & .35 \\
5 & 2.25 & 4.00 & 2.80 & .48 \\
6 & 1.25 & 4.00 & 2.80 & .48 \\
7 & 2.50 & 3.75 & 2.97 & .38 \\
8 & 1.00 & 4.00 & 2.57 & .71 \\
9 & 1.00 & 3.25 & 1.68 & .73 \\
10 & 1.00 & 3.25 & 2.42 & .62 \\
11 & 1.25 & 2.50 & 1.80 & .44 \\
12 & 1.00 & 2.25 & 1.73 & .43 \\
13 & 1.25 & 3.00 & 1.93 & .49 \\
14 & 1.00 & 3.00 & 2.67 & .59 \\
F1 & 2.70 & 3.70 & 2.98 & .29 \\
F2 & 1.50 & 3.75 & 2.54 & .50 \\
F3 & 1.29 & 2.67 & 1.83 & .35 \\
\hline & & & & \\
\hline
\end{tabular}

Note: 1 -Active coping, 2 -Planning, 3 - Suppression of competing activities, 4 -Restraint coping, 5 -Seeking social support for instrumental reasons, 6 -Seeking social support for emotional reasons, 7 -Positive reinterpretation and growth, 8 -Denial, 9 -Acceptance, 10 -Turning to religion, 11 -Focusing on and venting of emotions, 12 -Behavioral disengagement, 13 -Mental disengagement, 14-Alcohol drug disengagement, F1 - cognitive engagement, F2 - emotional engagement, F3 - cognitive and emotional disengagement.

In order to reveal the correlations between the researched indexes we applied correlation analysis (criterion of Spearman). There are certain interdependencies between state anxiety and perceived stress at the beginning of the expedition, as well as with the manifestations of trait anxiety (table 3 ). There is a correlation between trait anxiety at the beginning and at the end of the expedition, as well as with the results from the first evaluation of perceived stress. State anxiety at the end of the expedition correlates significantly with trait anxiety and perceived stress measured at the same time. The result from the second evaluation of trait anxiety correlates significantly with perceived stress at the beginning and at the end, as well as with the stress coping strategy. There are a number of interdependencies between the different stress coping strategies. 
Table 3. Correlation dependences between the researched parameters

\begin{tabular}{lccc}
\hline & State anxiety 1 & State anxiety 2 & Trait anxiety 1 \\
\hline State anxiety 1 & & & \\
\hline State anxiety 2 & ${ }^{\star} 0.453$ & & \\
\hline Trait anxiety 1 & ${ }^{\star} 0.875$ & & \\
\hline Trait anxiety 2 & ${ }^{\star} 0.562$ & ${ }^{\star} 0.539$ & ${ }^{\star} 0.564$ \\
\hline Perceived stress 1 & ${ }^{\star} 0.664$ & & \\
\hline Perceived stress 2 & & ${ }^{\star} 0.594$ & \\
\hline $\begin{array}{l}\text { F2 emotional } \\
\text { engagement }\end{array}$ & ${ }^{\star} 0.465$ & \\
\hline $\begin{array}{l}\text { F3 cognitive } \\
\text { and emotional } \\
\text { disengagement }\end{array}$ & & ${ }^{\star} 0.367$ & \\
\hline
\end{tabular}

In conformity with the aim of the research a step regression analysis was used. The independent variables were the perceived stress at the beginning and at the end of the expedition. The dependent variables were state anxiety at the beginning and at the end of the expedition. We found out that the high level of perceived stress at the beginning of the expedition influenced state anxiety, measured at the beginning of the expedition $(\beta=0,64 * *)$ (table 4$)$.

Table 4. Results from the regression analysis -1

\begin{tabular}{llccc}
\hline \multirow{2}{*}{ Index } & \multicolumn{3}{c}{ Perceived stress in the beginning } & \multirow{2}{*}{$\Delta R^{2}$} \\
\cline { 2 - 5 } & $\beta$ & $\mathrm{t}$ & .Sig & \\
\hline State anxiety in the beginning & 0,640 & 3,228 & 0,006 & 0,410 \\
\hline
\end{tabular}

There is an analogical trend at the end of the expedition, and the result is even more significant $\left(\beta=0,85^{* *}\right)$ (table 5$)$.

Table 5. Results from the regression analysis -2

\begin{tabular}{lllll}
\hline Index & \multicolumn{3}{l}{ Perceived stress in the end } & \\
\cline { 2 - 5 } & $\beta$ & $\mathrm{t}$ & \multicolumn{1}{c}{ Sig } & \multicolumn{2}{c}{$R^{2}$} \\
\hline State anxiety in the end & 0,815 & 4,665 & 0,001 & 0,634 \\
\hline
\end{tabular}

In the next regression model the role of dependable variables was taken by the three generalized secondary factors of stress coping strategies. We did not find any influence of the perceived stress and state anxiety on the preference to certain stress coping strategies. 


\section{DISCUSSION AND CONCLUSION}

Antarctica's extreme conditions can provoke important cognitive and behavioral changes in the members of polar expeditions. However, these changes may result in a successful adaptation to the environment, i.e., salutogenic effects that might generate feelings of self-efficacy and a significant improvement in general health. Despite this, distress related to the expeditions' social and physical characteristics should not be overlooked, as the impact of stressors can impair individual and team performance and compromise crew members' health. Understanding and categorizing these effects is of major importance for the prevention of negative factors related to the psychosocial and neuropsychological adaptation brought about by unusual environmental conditions.

Palinkas and Suedfeld (2008) showed depression as one of the most common symptoms in Antarctic expeditions, followed by anxiety and irritability, thereby, even with few cases requiring clinical intervention, neglect of these factors could have serious consequences. The decrease in life and work satisfaction during a long period in Antarctica is frequently reported in the articles. This is mostly reported as temporary, i.e., as stages or a linear pattern for the adaptation to the environmental stressors (Palinkas \& Houseal, 2000). Nevertheless, environmental challenges may bring about stress, due to the overcoming of difficulties imposed upon polar teams (Norris, Paton \& Ayton, 2010; Weiss, Suedfeld, Steel \& Tanaka, 2000). After analyzing data referring to research reports, strong evidence supports the perspective that coping strategies can produce long-term salutogenic reactions in the expedition members' lives (Norris et al., 2010; Peri, Scarlata \& Barbarito, 2000; Palinkas \& Suedfeld, 2008). Accordingly, an increasing number of studies have been performed that are directed toward the understanding of the protection factors associated with well-being and professional performance under conditions of extreme adversity.

On the base of the obtained results it could be summed up that the participants in the XXV Bulgarian Antarctic expedition are characterized with levels of perceived stress and state and trait anxiety within the norm for Bulgarian population. There is a significant decrease in the level of the abovementioned variables at the end of the expedition, which meets our expectations.

Similar results were obtained when we used Spielberger's state Anxiety Scale. It was administered to the Indian scientists across three different periods of Antarctic expedition, namely, onward, stay and return journey from Antarctica. One way ANOVA with repeated measures (45 observations) shows that state anxiety score during onward journey to Antarctica was significantly higher than that of other periods (Roy, 1996).

The most preferred strategies for coping with stress and anxiety in sport activities with all groups of participants in the research are problem focused strategies. The least used coping strategies with all groups of participants in the research are strategies connected with a passive approach to the stressor.

The data obtained from our study suggest that the people surveyed are significantly more resilient in extreme situations, threatening incentives in situations of danger and risk, their anxiety is controlled, relying heavily on their internal resources, on their own capabilities in situations of threat.

When researching the cultural context of stress, illness and coping in Antarctica Palincas (1992) is examined in the context of the human experience in Antarctica. This experience is characterized by prolonged isolation, confinement, and exposure to extreme environmental conditions. Men and women who winter-over at scientific research stations often exhibit a complex of psychophysiological symptoms in response to these stressors. How- 
ever, this experience also appears to provide long-term health benefits. It is argued that the psychological symptoms are themselves part of the process of coping and do not necessarily represent an inability to adapt to the extreme environment. Coping is viewed as a process of negotiation leading to a compromise between individual and group needs. Further, this process fosters the acquisition of new strategies or resources for coping with subsequent stressful experiences.

The limitations of the present study are connected with the relatively small number of researched individuals, but this is the number of the people who took part in the expedition.

It is important to highlight that the logistical difficulties and the generally reduced number of research samples are inherent characteristics to Antarctic expeditions, which makes the accumulation of data in this area slow and sparse.

Thus, this studies provides information about what can be done to promote satisfactory adaptation and reduce the psychological distress in these people. The research adds to the understanding of the factors propelling human behavior, which are the base for participation in hard and challenging missions in extreme environment in different parts of the world.

\section{REFERENCES}

Anshel, M. H. Toward validation of a model for coping with acute stress in sport. International Journal of Sport Psychology, 21, 58-83, 1990.

Carver, C., J. Weintraub, M. Scheier. (1989). Assessing coping strategies: a theoretically based approach. Journal of Personality and Social Psychology, 56.

Folkman, S. (1992), Making the case for coping. In B. Carpenter (Ed.) Personal coping: Theory, Research, and Application, pp.31-46. New York: Prager.
Folkman, S., R. Lazarus. (1980). An analysis of coping in middle - aged community sample.Journal of Health and Social Behavior, No 21.

Georgiev, M., G., Domuschieva-Rogleva, I. Tosheva. (2003). Vtorichni faktori i optimizirane na testa za izsledvane na predpochitanite strategii za spraviane sys stresa - COPE - 1. - V: Lichnost, Motivaciia, Sport. Knigi 13.Prosport.S. (in Bulgarian).

Georgiev, M., G., Domuschieva-Rogleva, I. Tosheva. (2009). Eksploratoren I konfirmatoren faktoren analiz na predpochitanite strategii za spraviane sus stresa - - COPE - 1 V: Lichnost, Motivaciia, Sport. T. 14, NSA, 151-160.

Gould, D., Finch, L.M., \& Jackson, S.A. Coping strategies used by national champion figure skaters. Journal of Sport and Exercise Psychology, 15, 134-159, 1993.

Gunderson, E. K. E. (1974). Psychological studies in Antarctica. In E.K.E.Gunderson (Ed.), Human Adaptability to Antarctic Conditions (pp. 115-131). Washington, DC: American Geophysical Union.

Gunderson, E. K. E. and Palinkas, L. A. (1991). Psychological studies in the U.S. Antarctic program: A review. Scott Polar Research Institute Polar Symposia, 1, 5-8.

Karastoyanov, G., A. Rusinova-Hristova. (2000), Bulgarska adaptatsiya na vaprosnika zza vazpriet stress, Psihologichni izsledvaniya, 1-2, 2000. / Българска адаптация на въпросника за възприет стрес. Психологични изследвания, 1-2, 2000.

Khandelwal SK, Bhatia A, Mishra AK., Psychological health in the summer team of an Indian expedition to Antarctica. J Ment Health Hum Behav. 2015;20:65-70.

Khandelwal SK, Bhatia A, Mishra AK., Psychological adaptation of Indian expeditioners during prolonged residence in Antarctica.Indian J Psychiatry. 2017 Jul-Sep; 59(3): 313-319.

King, J.C. \& Turner, J. 1997.Antarctic me- 
teorology and climatology. Cambridge: Cambridge University Press, 409 pp.

Kirkpatrick, A. (2011). Cold wars: Climbing the fine line between risk andreality. Sheffield, England: Vertebrae Graphics.

Larsen, R., Billings, D., Cutler, S. (1996). Affect intensity and individual differences in informational style, Journal of Personality, 64, 185-207.

Lazarus, R S, (1966). Psychological Stress and the Coping Process. New York: McGrawHill

Lazarus, R.S., \& Folkman, S. (1984). Stress, appraisal, and coping, NY: Springer.

Leventhal, E. A., Suls, J., \& Leventhal, H. (1993). Hierarchical analysis of coping: Evidence from life-span studies. In H. W. Krohne (Ed.), Attention and avoidance (pp. 71-99). Seattle, WA: Hogrefe \& Huber.

Lugg, D.J. 2005. Behavioural health in Antarctica: behavioural implications for longduration space missions. Aviation, Space, and Environmental Medicine, 76, 74-77.

Martens, R., R. Vealey, D. Burton.(1990). Competitive anxiety in sport.Human Kinetics Publishers.

Mishra V., (2006). Stress, Anxiety and Loneliness Among 20th Indian Expeditioners at Antarctica during Summer.Twentieth Indian Expedition to Antarctica, Scientific Report, Ministry of Earth Sciences, Technical Publication No. 18, pp 233-241

Norris K., Paton D., Jeff Ayton J.,Review. (2010), Future directions in Antarctic psychology research.Antarctic Science 22(4), 335-342

Palinkas LA., 1992 Going to extremes: The cultural context of stress, illness and coping in Antarctica. Soc Sci Med. 35:651-64.

Palinkas, L. A. and Johnson, J. C. (1990). Social relations and individualperformance of winter-over personnel at McMurdo station. Antarctic Journal 23, 238-240.

Palinkas, L. A., Suedfeld, P. and Steel, G. G. (1995). Psychological functioningamong members of a small Polar expedition. Aviation,
Space, and Environmental Medicine,66(10), 943-50.

Palinkas, L. A., Suedfeld, P. (2008). Psychological effects of polar expeditions.Lancet. Jan 12;371(9607):153-63.

Palinkas, L.A. (2003). The psychology of isolated and confined environments: understanding human behaviour in Antarctica. American Psychologist, 58, 353-363.

Rosnet, E., LeScanff, C. and Sagal, M.S. (2000). How self-image and personalityinfluence performance in an isolated environment. Environment and Behaviour, 32(1), 18-31.

Roy, D. D., (1996), Differential patterns of state anxiety of scientists during antarctic expedition. Journal of the Indian Academy of Applied Psychology. Jan-Jul; 22(1-2): 43-5

Rusinova-Hristova, A., G. Karastoyanov, (2000).Psihologicheskite tipove po Karl Ung i stresut, C. (In Bulgarian).

Sagar R, Pattanayak RD. "To the ends of the earth and beyond": Psychological aspects of circumpolar expeditions. $J$ Mental Health Hum Behav 2015;20:45-7

Selye H. (1956). The stress of life. New York: McGraw-Hill Book Co.

Shtetinski, D., Paspalanov, I. (1989).Metodichesko posobie za rabota s bulgarskata forma na vuprosnika za ocenka na trevojnostta na Ch. Spilburgur, S., BAN. (In Bulgarian).

Singer, R. N. (1982). Thought processes and emotions in sport.The Physician and Sports Medicine, 10, 75-88.

Smith , R. E. (1986). Toward a cognitiveaffective model of athletic burnout. Journal of Sport Psychology, 8, 36-50, 1986.

Spielberger, C.D. (1983) State-Trait Anxiety Inventory STAI. Consulting Psychologists Press, Palo Alto.

Suedfeld, P. (2001). Applying positive psychology in the study of extremeenvironments, Human Performance in Extreme Environments, 6(1), 21-25.

Zimmer M; Cabra JCCR; Borges FC; Côco KG; Bianca da Rocha Hameister 
BR.,Psychological changes arising from an http://dx.doi.org/10.1590/

Antarctic stay: systematic overview.Estud. S0103166X20130003000

psicol. (Campinas) vol.30 no.3 Campinas

July/Sept. 2013.

Correspondence:

Galina Domuschieva-Rogleva

National Sports Academy "Vassil Levski"

Department of Psychology, Pedagogy and Sociology

Studentski grad, 21, Acad. Stefan Mladenov Str.

Sofia 1700, Bulgaria

E-mail: galinarogleva@abv.bg 